\title{
Access to Primary Care for Persons Recently Released From Prison
}

\author{
Nabla Fabmy, $M D^{1}$ \\ Fiona G. Kouyoumdjian, $M D$, \\ $\mathrm{MPH}, \mathrm{PbD}{ }^{2,3}$ \\ Jonathan Berkowitz, $P b D^{1}$ \\ Sharif Fabmy, MBA ${ }^{1}$ \\ Carlos Magno Neves, $M A^{4}$ \\ Stephen W. Hwang, $M D^{3}$ \\ Ruth Elwood Martin, MD, MPH \\ 'University of British Columbia, Vancouver, \\ British Columbia, Canada \\ ${ }^{2}$ Department of Family Medicine, McMaster \\ University, Hamilton, Ontario, Canada \\ ${ }^{3}$ Centre for Urban Health Solutions, \\ St Michael's Hospital, Ontario, Canada \\ ${ }^{4}$ Universidade Federal de Santa Catarina, \\ Florianópolis, Brazil
}

\begin{abstract}
We aimed to determine if a history of recent imprisonment affects access to primary care. Using patient roles, we telephoned to request an initial appointment with all family physicians $(n=339)$ who were accepting new patients in British Columbia, Canada. We sequentially assigned patient scenarios: male or female recently released from prison; male or female control. Controls were 1.98 (95\% $\mathrm{Cl}, 1.59-2.46)$ times as likely to be offered an appointment compared with persons recently released from prison, with an absolute risk difference of $41.8 \%$ (95\% Cl, 31.0-52.5). Our study suggests discrimination is a barrier to primary care for people released from prison, even with universal health insurance. We need to improve access to primary care during the high-risk period following prison release.
\end{abstract}

Ann Fam Med 2018;16:549-551. https://doi.org/10.1370/afm.2314.

\section{INTRODUCTION}

I

mprisonment is a common experience in Canada and the United States, with cross-sectional rates of 106 per 100,000 in Canada and 698 per 100,000 in the United States. ${ }^{1}$ People who experience imprisonment have high rates of morbidity and mortality, ${ }^{2}$ particularly around the time of release from prison. ${ }^{3-5}$

Primary care provides an opportunity to manage ongoing illness, prevent disease, and address social determinants of health. ${ }^{6}$ In the United States, lack of health insurance has been identified as a significant barrier to primary care access for persons after release from prison. ${ }^{7}$ This should not be a barrier in Canada where a universal health care system exists and family physicians (FPs) are reimbursed for patient care by the government In addition, people with a history of imprisonment (or other involvement with the criminal justice system) experience discrimination in health care and other settings ${ }^{8-10}$ although this research is limited.

Our objective was to determine whether a history of recent release from prison affects access to primary care in Canada.

\section{METHODS}

\section{Setting}

The study was conducted in British Columbia, Canada.

\section{Participants}

Conflicts of interest: authors report none.

In August 2016, we downloaded a list of all family/general physicians (FPs) who were accepting new patients from the website of the College of Physicians and Surgeons of British Columbia. The list was alphabetical by town or city of practice and by physician last name within each town or city.

\section{Design}

We used unannounced telephone calls to the offices of FPs who were accepting new patients. We sequentially assigned each FP on the list to 
receive a single telephone call using 1 of 4 patient scenarios: (1) male recently released from prison, (2) female recently released from prison, (3) male control, or (4) female control. Three research team members, 2 male and 1 female, placed the telephone calls in 2017 using a standardized script (Table 1). If an appointment was scheduled, it was cancelled within 1 day and before the scheduled appointment.

\section{Outcome}

The primary outcome was whether the telephone caller was offered an appointment. We defined a positive response as being offered an appointment with the FP on the list or with another FP in the same practice, or being placed on a waiting list for new patients. We defined a negative response as not having an appointment offered and not being placed on a waiting list.

\section{Analysis}

We compared the proportion of positive responses by imprisonment history using $\chi^{2}$ tests for all telephone calls and by the sex of the telephone caller. We calculated the risk difference and risk ratio with 95\% CIs.

We used $\chi^{2}$ tests to compare physician sex (data from College of Physicians and Surgeons of British Columbia registry) and practice rurality (data from University of British Columbia Department of FP residency program) based on the assigned scenario.

\section{Ethics Review}

The University of British Columbia Behavioral Research Ethics Board approved the study (H16-

Table 1. Telephone Scripts Used to Request an Initial Appointment With a Primary Care Physician

\begin{tabular}{ll}
\hline Patient Scenario & Script \\
\hline Opening (both scenarios) & $\begin{array}{l}\text { Hello? Is this } \mathrm{Dr} \\
\text { explicitly by the person answering the telephone.) }\end{array}$ \\
$\begin{array}{ll}\text { Recent release from prison } & \text { Hi. I was just released from prison a few months ago and } \\
\text { I need a family doctor for regular checkups. }\end{array}$ \\
$\begin{array}{ll}\text { Is Dr } \\
\text { Hi. I need a family doctor for regular checkups. } \\
\text { Is Dr accepting new patients? }\end{array}$
\end{tabular}

Table 2. Outcome of Requests for an Initial Appointment With a Primary Care Physician ( $\mathrm{N}=250)$

\begin{tabular}{lcccc}
\hline Patient Scenario & $\begin{array}{c}\text { Positive } \\
\text { No. (\%) }\end{array}$ & $\begin{array}{c}\text { Negative } \\
\text { No. (\%) }\end{array}$ & $\begin{array}{c}\text { Risk Difference } \\
(\mathbf{9 5 \%} \mathbf{C l})\end{array}$ & $\begin{array}{c}\text { Risk Ratio } \\
\text { (95\% CI) }\end{array}$ \\
\hline $\begin{array}{l}\text { Recent release from } \\
\text { prison }(\mathrm{n}=122)\end{array}$ & $52(42.6)$ & $70(57.4)$ & (reference) & (reference) \\
\begin{tabular}{l} 
Control $(\mathrm{n}=128)$ \\
\hline Note: $P<.001$ for $\chi^{2}$ test comparing percent with a positive response between the 2 scenarios.
\end{tabular}
\end{tabular}

02861). Although the study involved a minor deception and was conducted without participant informed consent, this was deemed acceptable given the lack of participant risk, the minimal burden of study participation, and the fact that obtaining informed consent would alter participant behavior in a way that would render the results invalid. After we completed data collection, we sent a brief summary disclosing the study to all FPs who received a telephone call.

\section{RESULTS}

Of 339 FPs identified as accepting new patients, 49 offices did not answer the telephone, telephone calls to request appointments with 8 FPs were directed to 3 other FPs on the list, and 32 FPs were excluded due to incorrect telephone number, retired physician, or the physician not providing primary care. Our final sample was 250 FPs.

Telephone callers who presented as recently released persons were significantly less likely to receive a positive outcome when compared with controls $(P<.001)$. An appointment was offered to $42.6 \%$ of telephone callers presenting as recently released from prison, compared with $84.4 \%$ of control telephone callers (Table 2). The likelihood of obtaining an appointment was 1.98 (95\% CI, 1.59-2.46) times greater for controls compared with those reporting recent release from prison, and the absolute difference was $41.8 \%$ (95\% CI, 31.0-52.5). There was no significant difference in whether an appointment was offered between male and female telephone callers $(P=.42)$.

There was no difference between characteristics of FPs assigned to a recently released scenario compared with those assigned to a control scenario in terms of physician sex (63.9\% vs $64.8 \%, P=.88)$ or physician practice rurality $(62.3 \%$ vs $68.8 \%, P=.28)$.

\section{DISCUSSION}

In this study, researchers who presented as having recently been released from prison were significantly less likely than controls to be offered an initial appointment with a primary care physician. Controls were twice as likely to obtain an appointment compared to those presenting as recently released from prison. There was no difference in the likelihood of obtaining an 
appointment between male and female telephone callers who reported recent release.

There are several limitations to this study. First, we did not randomize the scenario assignment; however, we found no difference in sex or rurality of FP offices assigned to the different scenarios. Second, some persons might not disclose recent release from prison on an initial telephone call with office staff. Anecdotally, the history of imprisonment is often shared when requesting an appointment for primary care, to justify why people are looking for a primary care physician, by a third party such as a correctional health care provider arranging care around the time of release, or through sharing documents that say the prison name, such as a prescription or medication list. Third, we did not assess office staff attributes, which were potential confounding factors; access to care and quality of care may be impacted by interactions with health care staff.

This study suggests that discrimination on the basis of recent imprisonment may be a barrier to access to primary care, even in the context of a universal health care system. Further study is needed to understand factors that influence discrimination. In addition, building on evidence-based strategies, ${ }^{6,11,12}$ policies and programs are needed to support people in accessing indicated health care during the challenging and highrisk transition from prison to the community.

To read or post commentaries in response to this article, see it online at http:I/www.AnnFamMed.org/content/16/6/549.

Key words: prisoners; prisons; primary health care; discrimination

Submitted February 26, 2018; submitted, revised, August 13, 2018; accepted September 5, 2018.

Funding support: Dr Nahla Fahmy conducted this study while she was a family practice resident at the University of British Columbia. No funding support was received for this research, which was conducted as a component of Nahla Fahmy's graduation requirements for the postgraduate family medicine residency program at the University of British Columbia.

Previous presentation: A version of this paper was presented at the Family Medicine Forum, November 8-11, 2017, Montréal, Canada.
Authorship contributions: N.F., R.E.M., F.K., and S.H. were involved in the study design and drafting of the manuscript. N.F., S.F., C.M.N., and R.E.M. contributed to data collection. J.B. and F.K. conducted the analysis. R.E.M. had full access to all of the data in the study and takes responsibility for the integrity of the data and the accuracy of the data analysis. All authors assisted with interpretation of findings, manuscript revision, and approval of the final manuscript.

\section{References}

1. Walmsley R. World Prison Population List. 11th ed. London, England: Institute for Criminal Policy Research; 2016.

2. Fazel S, Baillargeon J. The health of prisoners. Lancet 2011; 377(9769):956-65.

3. Baillargeon J, Hoge SK, Penn JV. Addressing the challenge of community reentry among released inmates with serious mental illness. Am J Community Psychol. 2010;46(3-4):361-375.

4. Binswanger IA, Blatchford PJ, Mueller SR, Stern MF. Mortality after prison release: opioid overdose and other causes of death, risk factors, and time trends from 1999 to 2009. Ann Intern Med. 2013; 159(9):592-600.

5. Baillargeon J, Giordano TP, Rich JD, et al. Accessing antiretroviral therapy following release from prison. JAMA. 2009;301(8):848-857.

6. Wang EA, Hong CS, Shavit S, Sanders R, Kessell E, Kushel MB. Engaging individuals recently released from prison into primary care: a randomized trial. Am J Public Health. 2012;102(9):e22-e29.

7. Rich JD, Chandler R, Williams BA, et al. How health care reform can transform the health of criminal justice-involved individuals. Health Aff (Millwood). 2014;33(3):462-467.

8. Frank JW, Wang EA, Nunez-Smith M, Lee H, Comfort M. Discrimination based on criminal record and healthcare utilization among men recently released from prison: a descriptive study. Health Justice. 2014;2:6.

9. Pager D. The mark of a criminal record. Am J Sociol. 2003;108(5): 937-975.

10. Turney K, Lee H, Comfort M. Discrimination and psychological distress among recently released male prisoners. Am J Mens Health. 2013;7(6):482-493.

11. Kinner SA, Alati R, Longo $M$, et al. Low-intensity case management increases contact with primary care in recently released prisoners: a single-blinded, multisite, randomised controlled trial. J Epidemiol Community Health. 2016;70(7):683-688.

12. Wang EA, White MC, Jamison R, Goldenson J, Estes M, Tulsky JP. Discharge planning and continuity of health care: findings from the San Francisco County Jail. Am J Public Health. 2008;98(12): 2182-2184. 